\title{
IOT based smart home
}

\author{
Mahmood Talib Al Sheyadi \\ Muhammad Sohail
}

\author{
Middle East College \\ Middle East College
}

\begin{abstract}
With the great development in all areas of our lives, especially communications and electronics, which is the basic component of any service or industry. By exploiting this development and incorporating it into our daily lives and in the tools we use, our lives are gradually transformed into easier and more choices. This project is an example of Exploitation of technologies in a way that serves the need of human security and safety. By sing the available communication and electronics technologies, it is possible to modify and improve homes to be safer and safer (Vermesan et al., 2017). The idea of the project is to connect all parts and appliances to a system that allows them to communicate with each other in the first place and on the other hand allows the user to control them remotely and monitor all the developments and notifications of each system and this called IOT system (Lobaccaro, Carlucci, \& Löfström, 2016). The application of this type of system is possible to control all the food of the house and identify everything from the security system to the lighting system and air conditioning. For example, the domestic fire system, in the new system is able to identify all types of gases and evaluate the appropriate solution to get rid of gas and avoid danger and inform the owner of accurate information. Unlike the old system, which triggers the alarm in all halal and does not recognize many of the deadly gases that may kill everyone in the house. Determine the cause of the problem. The system can communicate with all parts of the house, get rid of the risk causes, and avoid all risks. As well as the system for all other devices, it is possible to save energy as the work of the devices depends on the sensors of the need to work (Díaz, Martín, \& Rubio, 2016). Overall, the system consists of smart sensors for every part of the house that recognize everything and monitor all changes and risks around the clock.
\end{abstract}

\section{Introduction}

Nowadays the network is invade the world; it is interesting everything in the life to make it easier and advanced. A priority will be the safety and security of the chirp and the family, including homes and places where people are often present. Internet of things are software, interconnected computing devices, devices, digital devices, topics or people that are presented with special features, and they can transform facts across a network alongside painful human beings interacting with the computer. Internet of things (IOT) is the new generations of systems and networking where humans will do all the work in one task without any intervention (Angelini, Mugellini, Abou Khaled, \& Couture, 2018). This type of system is coming will many new features, which will allow controlling things and getting more information in the life we are leaving. On the other hand, this type of system will allow machine-to-machine communication, which is giving better results and less mistakes. In our life, there are many usages of the IOT systems to get more safety and security. IOT is a system using sensors and monitors to get the right information on time and get the order to the right part and machine to take the action. By give the need of the system and the signs to take the action the system will be monitoring and waiting to get the sine and take the action (Madakam, Ramaswamy, \& Tripathi, 2015). For example, the domestic fire system, in the new system is able to identify all types of gases and evaluate the appropriate solution to get rid of gas and avoid danger and inform the owner of accurate information. Unlike the old system, which triggers the alarm in all halal and does not recognize many of the deadly gases that may kill everyone in the house. Determine the cause of the problem. Figure 1 is showing the main components of IOT system. 


\section{Journal of Student Research}

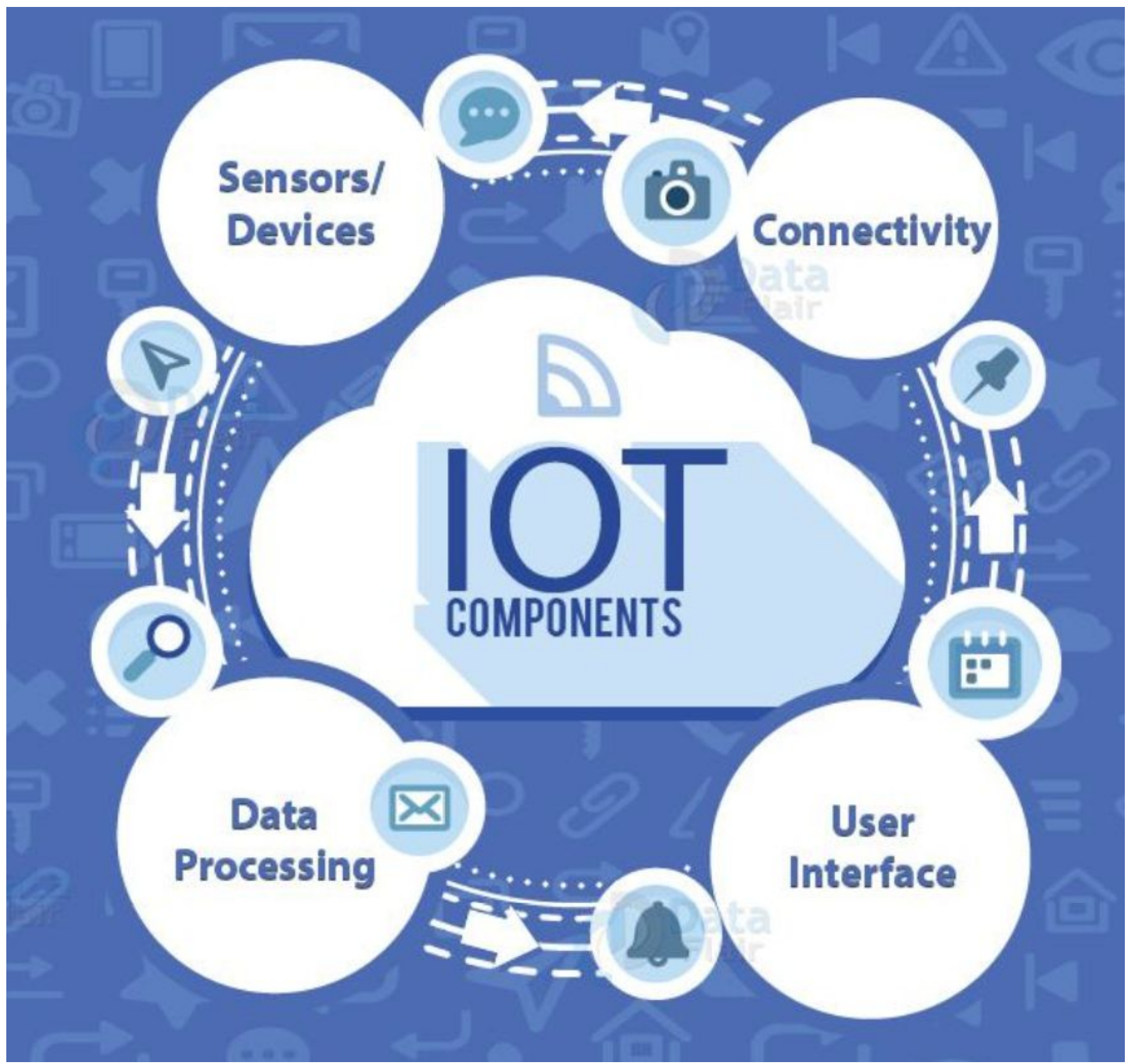

Figure 1. IOT system components

The main components of IOT system are four components presenting the parts of the IOT system. The first component is the Sensor and devices of the system (Kharchenko, Kondratenko, \& Kacprzyk, 2017). As the information and data will be collected and monsters by this part of the system. The information and data used to monitor and evaluate according to the required and needed. The sensors are the main part in the IOT system as the work of the other parts according to the information and data collected by the sensors. The Data processing is the stage of evaluation to check the required input from the sensors to start the action. This stage done in the controller of the IOT system, which programed according to the need of any task (Zhang \& Wen, 2017). The controllers of the IOT acting as small computer where it can control different devise at the same time. Moreover, the controller can be small for one task only, which is controlling only one devise. The third part is the user interface, which is the connection between the systems to the user. The user interface can be in different ways and for different tasks. The interface according to the user and the destination from the user, which is the available and required telecom paths. This part related to the system and it will present the way the system will interface with the normal network. 


\section{Journal of Student Research}

Fourth Middle East College Student Research Conference, Muscat, Sultanate of Oman

Finally, the Connectivity from the IOT system to the user and the sensors again. This connectivity is presenting the normal network connections and the bath of the telecommunication we have. By sing the available communication and electronics technologies, it is possible to modify and improve homes to be safer and safer. The idea of the project is to connect all parts and appliances to a system that allows them to communicate with each other in the first place and on the other hand allows the user to control them remotely and monitor all the developments and notifications of each system and this called IOT system (Lobaccaro et al., 2016). The application of this type of system is possible to control all the food of the house and identify everything from the security system to the lighting system and air conditioning.

\section{Problem statement:}

This project came to improve and enhance part of your life and solve some of the problems facing in our homes. By checking the old system of the homes we are using it has many problems and things we required to change it to get better life. Below will list all the Problem will solved by the IOT Home smart system. Since traditional homes follow the non-intelligent electrical system, which separates each device in the house from the other to the requirements of the electrical circuit, but this system created many problems with visiting the number of devices and the breadth of the house (Tayyaba, Khan, Ashraf, \& Balas, 2020).

- Manual system requires effort: The big effort required by the all-home system, as all the systems things are manual. On the other hand, the information and the capabilities of the old system is very limited.

- Difficult to control the house and manage it remotely: All components of the all house system aren't connected to each other including the internet access system. Therefore, the devices of the old system cannot share the information and cannot receive from the user any order. The main part of the IOT new house system is to gather the information from different devices and share it with the user to update any time it is required. On the other hand, the controller is giving the instructions received from the user with the device to take the required action accordingly.

- Wasteful electric power: At the all system, the device is having only the manual switch to work or not to work which mean the device will be working even if it is not required. This methodology of work is consuming high amount of power as the device is working with the full capacity all the time. At the new system, the device will not work unless it is required according to the sensors and analysis of the controller. In this case, of work, the system will require small amount of power for the sensors and the full capacity will not work all the time.

- Lack of knowledge if there is a fire at home: For the Fire system there are many things, which are making the old system not good and it is one of the main problems of the system. The old fire system does not recognize fires until after they have occurred, leaving no room for survival at times. As for the system the IOT home smart system it can identify the gases causing the fire and give the alarm in advance with the fill information. Moreover, the system can track the required action as it has the capability to contact and control all the devices of the house.

\section{Literature review}

Conventional homes follow the non-intelligent electrical system, which separates each device in the house from the other to the requirements of the electrical circuit. This system connects the devices to the electrical control panel, which monitors the sudden and large loss of electricity in the circuit and cuts off electricity. From the perspective of safety and security, the old system is not entirely 
security and there are many gaps pose a great danger to the members of the house. Loss of sensors in the traditional system prevents the identification of events and prevents the avoidance of risks. On the other hand, it is not possible to control any part of the house or even identify events that may be very important in the absence of residents. There are many cases where the residential were sleeping and things happen at the house such as thieves goes in or the house is on fire. The traditional home system cannot give any alarm or notification of the user, which make many problems and accidents.

To connect any system to the IOT or convert any home system to the IOT system need to have the main things to be add. Figure 2 is showing the main components need to be available at the IOT home system (Pandey, Kazmi, Hayat, \& Ahmed, 2017).

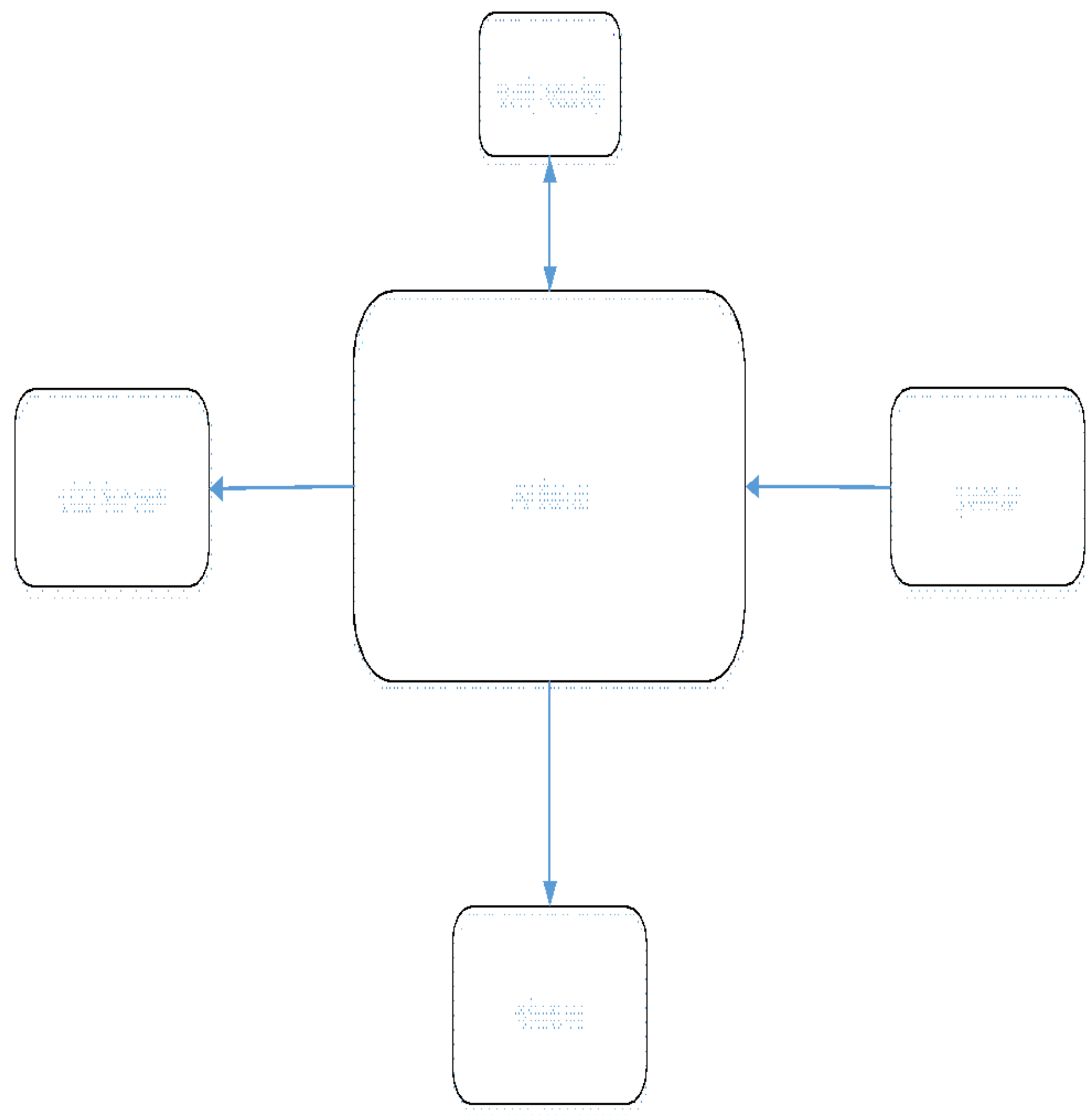




\section{Journal of Student Research}

Figure 2. Components of IOT home system.

To have any IOT system first need to have controller to control the information and requests from the other devices and the user. The controller will be having the capability to contact with the different devices at the house and to access to the internet to contact and update the user. To access to the internet will use the WiFi model, as the house will be having the WiFi server. If not the controller can connect to the network by using the SIM Model which can send the update tho the user directly (Al Mamari, Al Mamari, Kazmi, Pandey, \& Al Hinai, 2019). In the example the controller used in Arduino, one of the good controllers is programed and managed according to the need of the project. On the other hand, the user can connect and control any device at the house by using the same connection and the controller will send the request to the device.

To convert any house to IOT smart house must all sensors for the required action. The sensor will read all the inputs from the house and send the data to the controller so, it will be evaluated and tack the necessary action. Therefore, the sensor is very important, as it is the score of the information, which will cause the actions. Finally, the devices will get the instructions to take the action such as the Motor to open or close any access if needed. The LCD is show the message to the user or the available person. Moreover, the system will contact the user to give the needed information or update.

\section{Previous work done:}

Smart IOT home system is starting to be popular in all the word including Oman. There are some difference between the IOT systems used even at the same country. Some of the home systems are traditional systems but it is modified to the IOT system where it be partially IOT home systems. We can find these systems in Oman and many other countries. This system will be able to control part of the house according to the need of the customer. Therefore, this system designed for one user for some job. At figure 3 and 4 it show an example of the partial IOT home systems.

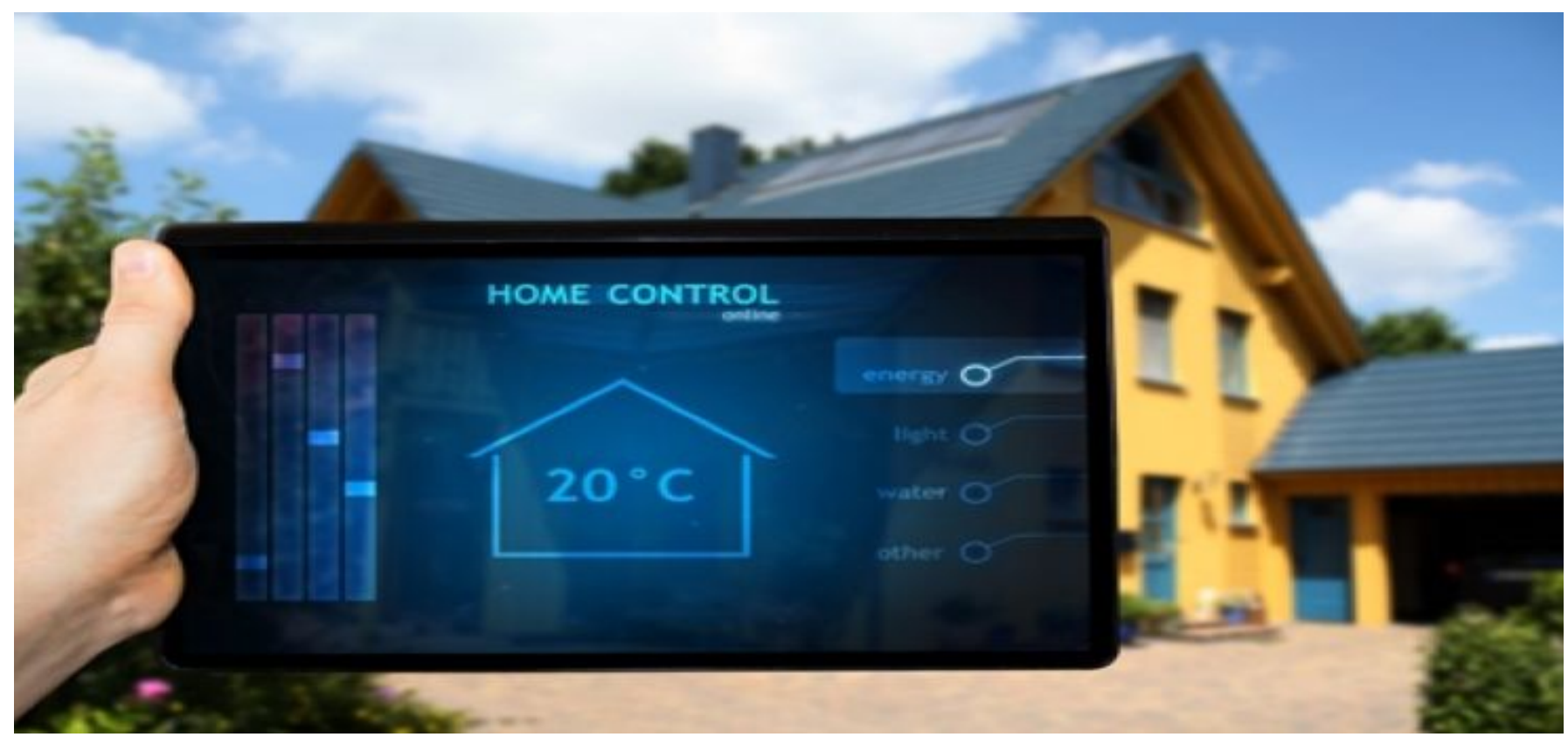

Figure 3. Partial IOT home systems 


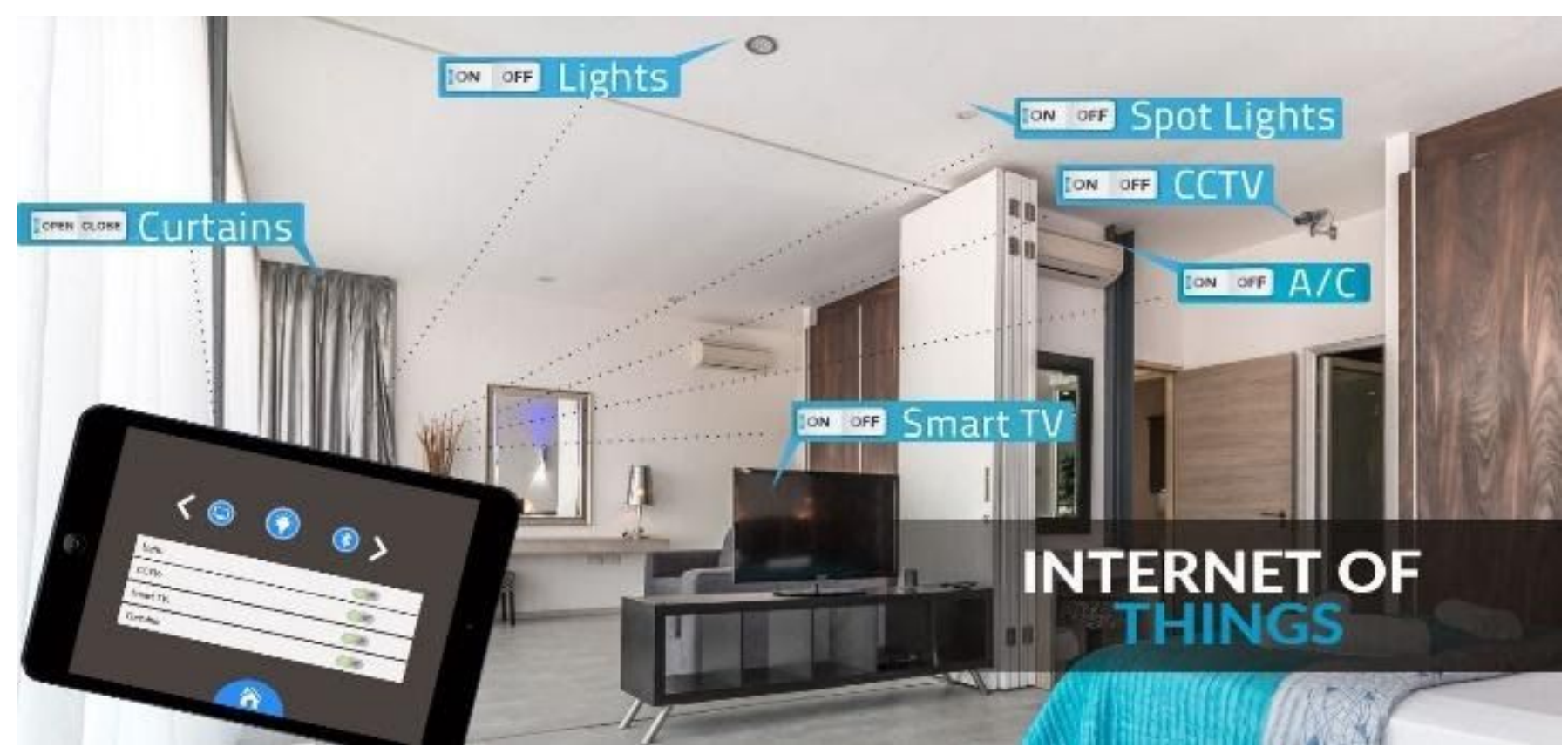

Figure 4. Partial IOT home systems

As it show at the Figure $3 \& 4$ the IOT home system is controlling part of the hose. In the first figure, the IOT system is to control the Energy, lights, Water and other for more options. The second designed to control Spotlights, CCTV, A/C Smart TV, Lights and the Curtains. Both home systems are made for the need of the user to control some of the devices at the house.

\section{Proposed system/architecture}

The system proposed in this project is to control the main parts of the home for more safety and save life environment. As the safety is one of the problems at the traditional system to things is propose at this system to achieve the following:

1. Fire system: the fire system in the traditional system is not helping the user to get the information and not taking the action to avoid the problems. The new fire system will include sensors to read all the gases in the house and identify it. This will help avoiding an accident such as fire ore suffocation because of the gases as it happened by the Cooking gas for a family. The IOT home system can track the action in these same cases to open the doors of the curtains to get rid of the gases from the house. To achieve the goal of the fire system the IOT system will control the curtains and the doors as will.

2. Security smart system: the normal traditional security systems will only raise an alarm at the house and all the cameras are working all the time. At the new IOT smart system the cameras will only work if the sensor feel there is any object is moving at the area. The object can be anything moving car, human, animal or anything. This system can help in saving the power and the capacity of the memory of the cameras. Moreover, the system will send notification with the record for the user to ask for action or it can take the action by closing the house or call the police as well.

The proposed system is controlling the house devices of the comfort such as the A/C Heaters. For this will add sensors for all the part of the house to check the temperature and according to the reading the $\mathrm{A} / \mathrm{C}$ will work or the heater to maintain the required home temperature. Moreover, there are many other features at the proposed system such as the car parking shade controlling, water controlling and others for any more need. 


\section{Architecture}

The architecture of the project is to convert the traditional system to the IOT system by adding new parts such as sensors and controller. As the project, will concentrate at the parts mentioned before. The project will include the Fire system sensors, the secretary sensors controlling the AC, heaters and the Water (Khatoun \& Zeadally, 2016). In addition to this, the project will include the control of the doors and curtains. The Project will include sensors to get the required information. Light sensor will give the information on the light level to control the light system at the home for saving power. The gaze sensors will be checking all the gases at the home and send the information to the Arduino to take the required action (Prakash \& Venkatram, 2016). The tradition system will only feel the smoke and take one action only which is the opening the water. The IOT fire system give the alarm and the notification for the user and open the doors and the windows (Andrés, Alejandra, Miguel, Augusto, \& Pedro, 2016). Figure 5 is showing the Block diagram of the project. 


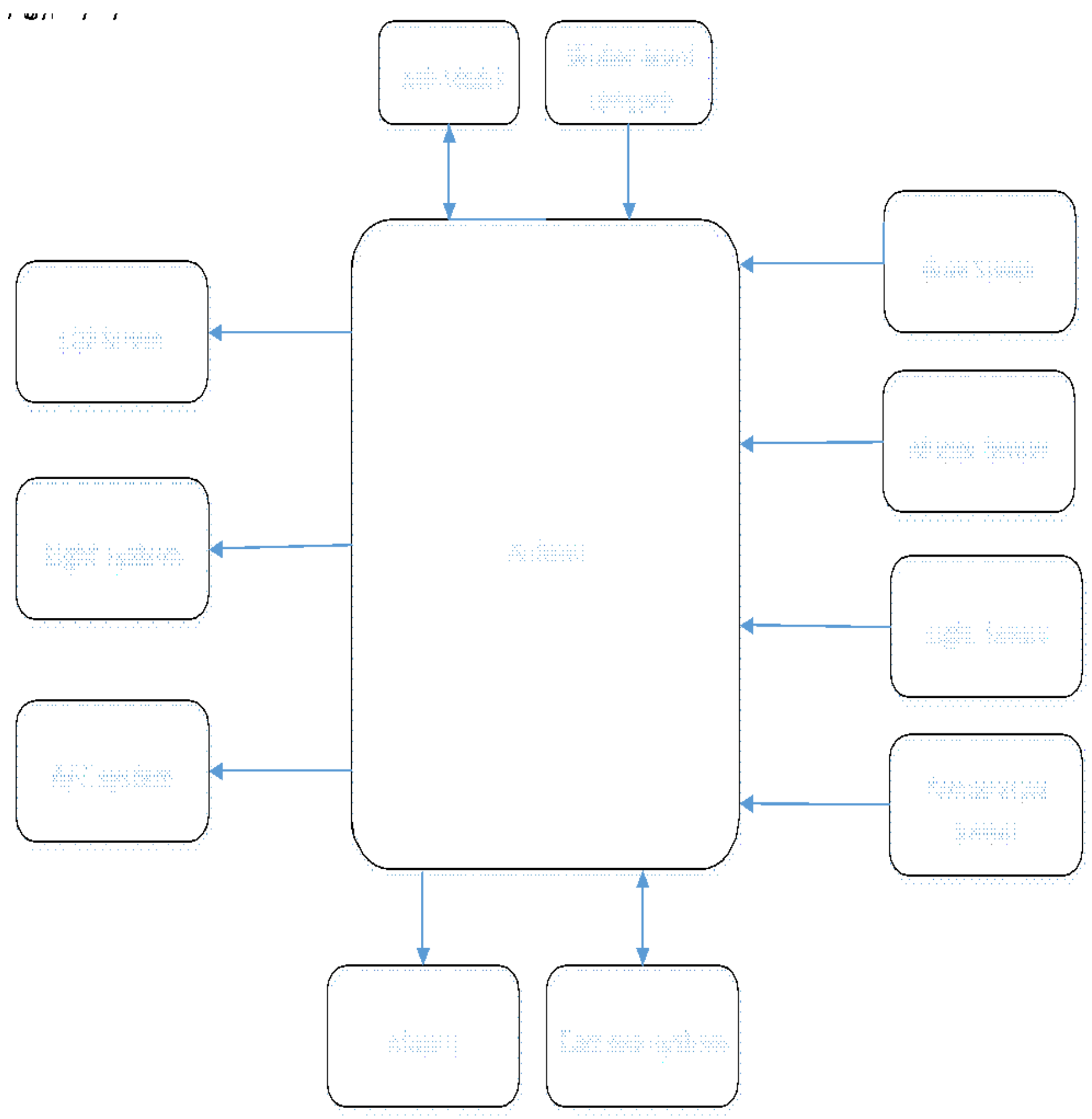

Figure 5. project Block diagram.

The Motors is add to open and close the doors and the windows. The instruction will be send from the controller to the motors to open or close the doors. The controller is receiving the instruction to open or close anything from the user throw the WiFi model. Moreover, the IOT system is controlling all the main parts of the house for more safety and comfort (Prakash \& Venkatram, 2016). The IOT system is controlling the house devices of the comfort such as the A/C Heaters. For this will add sensors for all the part of the house to check the temperature and according to the reading the A/C will work or the heater to maintain the required home temperature. Moreover, there are many other features at the proposed system such as the car parking shade controlling, water controlling and others for any more need. 


\section{Journal of Student Research}

\section{Results}

The sensors is collecting the data and information to be use and evaluated according to the requirements of the user. Below are some of the sensors used in the project:

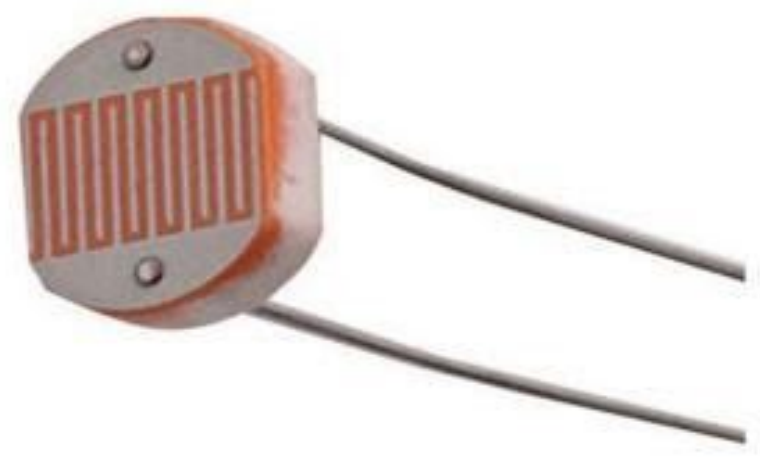

Figure 6. Light Sensor

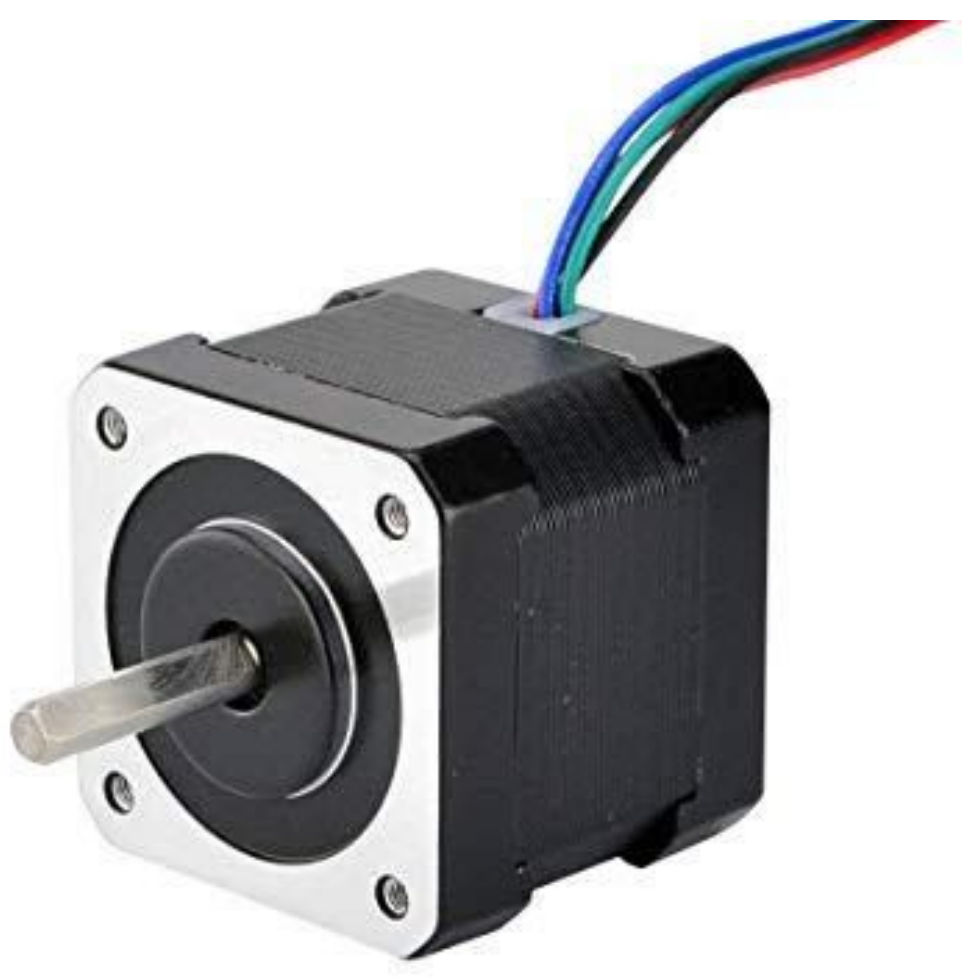

Figure 7. Motor 
Figure 6 is showing the light sensor, which is, used in the security system and the light system to reduce the power consumption. The motor used to open and close the doors, windows and the car parking shade.

Figure 8 is showing the controller of the project (Arduino) which is controlling all the project and devices.

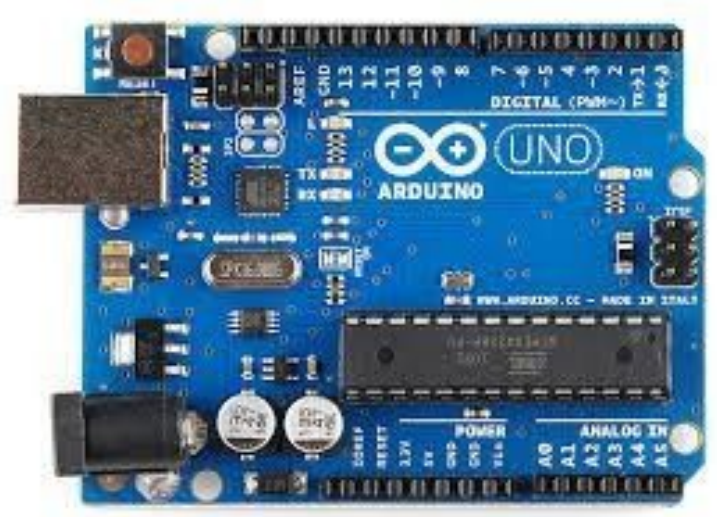

Figure 8. Project controller (Arduinos)

\section{Conclusion}

The research paper proposes the framework to transform traditional home into IOT based smart home after some modifications. By adding sensors, controllers and parts to the required devices will be able to control and get more information from it. By using the benefit of the new telecommunication system and the developed electronics systems it can make the life more save and more secure. This type of systems and projects helping to get the best living environment for the full family. Smart IOT home system is starting to be popular in all the word including Oman. There are some difference between the IOT systems used even at the same country. Some of the home systems are traditional systems but it is modified to the IOT system where it be partially IOT home systems. We can find these systems in Oman and many other countries. This project is an example of Exploitation of technologies in a way that serves the need of human security and safety. By sing the available communication and electronics technologies, it is possible to modify and improve homes to be safer and safer. The idea of the project is to connect all parts and appliances to a system that allows them to communicate with each other in the first place and on the other hand allows the user to control them remotely and monitor all the developments and notifications of each system and this called IOT system.

\section{References}

Al Mamari, A. R. M. H., Al Mamari, H., Kazmi, S. I. A., Pandey, J., \& Al Hinai, S. (2019). IoT based Smart Parking and Traffic Management System for Middle East College. Paper presented at the 2019 4th MEC International Conference on Big Data and Smart City (ICBDSC).

Andrés, B., Alejandra, F., Miguel, J., Augusto, S., \& Pedro, W. (2016). Towards the evolution of smart home environments: A survey. International Journal of Automation and Smart Technology, 6(3), 105-136.

Angelini, L., Mugellini, E., Abou Khaled, O., \& Couture, N. (2018). Internet of Tangible Things (IoTT): challenges and opportunities for tangible interaction with IoT. Paper presented at the Informatics. 


\section{Journal of Student Research}

Fourth Middle East College Student Research Conference, Muscat, Sultanate of Oman

Díaz, M., Martín, C., \& Rubio, B. (2016). State-of-the-art, challenges, and open issues in the integration of Internet of things and cloud computing. Journal of Network and Computer Applications, 67, 99-117.

Kharchenko, V., Kondratenko, Y., \& Kacprzyk, J. (2017). Green IT engineering: components, networks and systems implementation: Springer.

Khatoun, R., \& Zeadally, S. (2016). Smart cities: Concepts, architectures, research opportunities. Commun. Acm, 59(8), 46-57.

Lobaccaro, G., Carlucci, S., \& Löfström, E. (2016). A review of systems and technologies for smart homes and smart grids. Energies, 9(5), 348.

Madakam, S., Ramaswamy, R., \& Tripathi, S. (2015). Internet of Things (IoT): A literature review. Journal of Computer and Communications, 3(05), 164.

Pandey, J., Kazmi, S. I. A., Hayat, M. S., \& Ahmed, I. (2017). A study on implementation of smart library systems using IoT. Paper presented at the 2017 International Conference on Infocom Technologies and Unmanned Systems (Trends and Future Directions)(ICTUS).

Prakash, N. S., \& Venkatram, N. (2016). Establishing efficient security scheme in home IOT devices through biometric finger print technique. Indian Journal of Science and Technology, 9(17), 1-8.

Tayyaba, S., Khan, S. A., Ashraf, M. W., \& Balas, V. E. (2020). Home Automation Using IoT Recent Trends and Advances in Artificial Intelligence and Internet of Things (pp. 343-388): Springer.

Vermesan, O., Eisenhauer, M., Sundmaeker, H., Guillemin, P., Serrano, M., Tragos, E. Z., ... Bahr, R. (2017). Internet of Things cognitive transformation technology research trends and applications. Cognitive Hyperconnected Digital Transformation: Internet of Things Intelligence Evolution.

Zhang, Y., \& Wen, J. (2017). The IoT electric business model: Using blockchain technology for the internet of things. Peer-to-Peer Networking and Applications, 10(4), 983-994. 